\title{
ENFERMEIRO AUDITOR: O PROCESSO DE SOCIALIZAÇÃO NA ESCOLHA PROFISSIONAL ${ }^{1}$
}

\author{
AUDITING NURSE: THE SOCIALIZATION PROCESS IN PROFESSIONAL \\ CHOICE ${ }^{1}$
}

\author{
Magali Beatris Da Silva Monteiro ${ }^{1 *}$, Maria Angela Boccara De Paula ${ }^{2}$ \\ ${ }^{1}$ Mestre em Desenvolvimento Humano, Universidade de Taubaté (UNITAU), Taubaté, SP, Brasil, magali_beatris@yahoo.com.br ${ }^{*}$ \\ ${ }^{2}$ Doutora em Enfermagem, Universidade de Taubaté (UNITAU), Taubaté, SP, Brasil, boccaradepaula@gmail.com
}

\begin{abstract}
Resumo
A escolha profissional consiste em um momento de grande responsabilidade, na qual muitos jovens podem vivenciar este processo com grande dificuldade e incerteza. Lembrar momentos vividos pode promover segurança no momento da decisão final, por isso objetivou-se conhecer as influências dos processos de socialização, primária e secundária na trajetória profissional de uma enfermeira auditora (EA). Foi realizado um estudo de caso, a partir de uma pesquisa biográfica-narrativa, aprovada pelo CEP-UNITAU sob o número 2.975 .245 , com abordagem qualitativa, no vale do Paraíba paulista. Para a construção dos dados (auto)biográficos utilizou-se um formulário sociodemográfico e de formação da EA, e a entrevista biográfica, realizada em três momentos, a partir da seguinte questão desencadeadora: "Considerando que o processo de formação do enfermeiro constitui-se essencialmente para a prática assistencialista, conte-me como aconteceu sua trajetória profissional na AE?". A análise da narrativa permitiu verificar que a escolha da profissão foi um incidente crítico na trajetória profissional da EA, que ocorreu aos 20 anos de idade e foi caracterizada como período de desenvolvimento pessoal e profissional em sua vida. Assim, os grupos de socialização, primária e secundária, não só influenciaram como definiram sua escolha pela carreira, na qual acontecimentos e pessoas marcantes se mostraram especialmente importantes ao longo de sua trajetória profissional.
\end{abstract}

Palavras-chave: Enfermeiro auditor. Processo de socialização. Trajetória profissional. Desenvolvimento humano.

\begin{abstract}
The professional choice is a moment of great responsibility, in which many young people can experience this process with great difficulty and uncertainty. Remembering moments lived can promote security at the moment of the final decision, so it was aimed to know the influences of socialization processes, primary and secondary on the professional trajectory of an audit nurse (AE). A case study was carried out, based on a biographical-narrative research, approved by CEP-UNITAU under number 2,975,245, with a qualitative approach, in the Paraiba Valley of São Paulo. For the construction of (auto) biographical data, a sociodemographic and training form of the EA was used, and the interview biographical, carried out in three moments, from the following triggering question: "Considering that the process of training nurses is essentially for the care practice, tell me how your professional trajectory in AE happened?". The analysis of the narrative showed that the choice of profession was a critical incident in the professional trajectory of $E A$, which occurred at the age of 20 and was characterized as a period of personal and professional development in his life. So the socialization groups, primary and secondary, not only influenced but also defined their choice of career, in which remarkable events and people were especially important throughout their professional trajectory.
\end{abstract}

Keywords: Auditing nurse. Socialization process. Professional trajectory. Human development.

(C)UNIS-MG. All rights reserved. 


\section{INTRODUÇÃO}

A escolha da profissão não é tarefa fácil e nem mesmo ocorre de modo súbito, pois constitui-se em um importante passo na vida de um indivíduo. É uma decisão que muda seu futuro e determina o caminho no qual irá seguir, o ambiente ao qual pertencerá, assim como as pessoas com quem se relacionará ao longo de sua trajetória de vida.

Trata-se de um momento singular, de modo que qualquer dúvida ou questionamento pode ser considerado pelo indivíduo como um motivo que venha dificultar a definição de seu caminho profissional (NEPOMUCENO; WITTER, 2010; BOHOSLAVSKY, 2015).

Esse momento pode acarretar insegurança ao ter que decidir o que deseja fazer na vida ou qual trabalho realizar para atuar no mercado de trabalho. Processo que, por vezes, muitos jovens preferem ingressar em profissões que sabem que deram certo na família, e seguem a trajetória profissional de pais, avós ou outros familiares (LUCHIARI, 1996; DURAN, 2010).

No entanto, observa-se que três tipos de socialização permeiam a escolha profissional: a socialização primária, a socialização secundária e a socialização profissional. A primária ocorre a partir das (inter)relações primárias que o indivíduo estabelece ainda no contexto familiar, nos primeiros anos escolares e em grupos sociais, religiosos e culturais, seja por intermédio de professores, amigos ou colegas.

Esse primeiro tipo de socialização define a escolha de seu grupo de pertencimento, das pessoas com quem irá se relacionar e conviver ao longo de sua trajetória. Por isso, influenciam e podem contribuir para as escolhas, pessoais e profissionais, do indivíduo (HUTZ; BARDAGIR, 2006; ALMEIDA; SILVA, 2011; MIRANDA et al., 2015).

A família é um importante ponto de apoio nessa fase de contextualização e estruturação social, e porque não dizer, da própria construção identitária de cada sujeito. 0 ambiente familiar permite discussões e reflexões, que o apoiam ao longo de todo o processo de reconhecimento do tipo de atividade com a qual se identifica. É nesse meio que se rememora experiências e compartilha memórias que o direcionarão para o melhor caminho profissional (BERGER; LUCKMANN, 2004; SETTON, 2005).

Ainda assim, a trajetória profissional não se define pelas influências recebidas na infância, no núcleo familiar ou escolar. Estas são influências importantes, porém, não são definitivas. Escolher qual caminho seguir é um processo complexo, e que abarca a socialização secundária e profissional. A socialização secundária se dá por intermédio de pessoas nos demais anos escolares e grupos sociais, e trata-se de uma influência tão importante quanto à primeira, já que o indivíduo tem a oportunidade de amadurecer as inferências recebidas anteriormente, em virtude de sua maior capacidade de julgamento. Isso, tal como pontuou Ojeda et al. (2009) e Nepomuceno e Winter (2010), agrega valores e o auxilia a definir, alterar ou confirmar sua trajetória profissional.

No período em que a socialização secundária acontece, é comum que alguns jovens ainda indecisos, optem por ingressar em cursos técnicos. Essa escolha é uma estratégia, por vezes influenciada pelos próprios pais, que se sentem incumbidos de direcioná-los de alguma forma, como uma tentativa para que se identifiquem com alguma área específica, e quem sabe obter oportunidades significativas para seguir carreira (LUCHIARI (1996); BOHOSLAVSKY, (2015)).

A partir do início da vida profissional, novas perspectivas surgem e podem direcionar para novos rumos, construídos mediante o desenvolvimento da criticidade e reflexividade vivida em 
cada experiência (SHINYASHIKI et al., 2006). Assim, por intermédio de pessoas que significaram os momentos vividos ainda na infância, na adolescência ou já vida adulta, dá-se o seu desenvolvimento do indivíduo. Transformação que pode ser observada tanto no aspecto pessoal quanto no profissional, de modo particular e em diferentes temporalidades. Logo, o desenvolvimento do sujeito é contínuo.

Neste contexto, a socialização profissional, por sua vez, refere-se às influências vividas pelo indivíduo no ambiente de trabalho. Esse tipo de socialização ocorre a medida que a vida profissional acontece, seja na fase inicial, intermediária ou já na fase final da carreira. Isso porque as relações sociais no ambiente de trabalho nos afetam de modo particular, promovem amadurecimento, estabilidade e constante reavaliação da carreira profissional, até o seu desligamento e aposentadoria (HUBERMAN, (1995); VELOSO; DUTRA; NAKATA, (2016)).

Compreender, portanto, essas influências são tão importantes quanto à própria história do indivíduo. Cada história é construída a partir de um (re)começo, que se faz em meio as influências familiares, escolares, sociais e profissionais. Influências que ditam novas regras, novos valores, e por assim dizer, novos tons à vida. Por isso, identificar tais influências nas trajetórias profissionais de enfermeiras auditoras mostrou-se relevante, visto que tais profissionais passam por constante reestruturação ao longo da carreira.

A trajetória de vida de enfermeiros é repleta de particularidades comuns à profissão, como os desafios relacionados às questões históricas da Enfermagem, os aspectos salariais, as representações sociais, entre outros. Por esses motivos, a Enfermagem é uma das áreas que considera a biografização da vida de seus profissionais como uma forma de prestigiá-los, valorizálos pelo trabalho realizado, e uma maneira de enaltecer suas experiências na profissão e possibilitar discussões ao pleito de melhorias para todos (SANNA, 2011). Para isso,

\footnotetext{
As biografias ou trajetórias de vida das enfermeiras têm sido utilizadas na educação de enfermagem com várias finalidades - ressaltar o desenvolvimento de uma área profissional específica; orientar a criação de escolas de enfermagem e associações profissionais; criar teorias de enfermagem; investigar os avanços sociais e políticos da profissão (PADILHA; NELSON; BORENSTEIN, 2011, p. 248).
}

Diante disso, observou-se ao concluir uma pesquisa de mestrado que buscou conhecer a trajetória profissional de um determinado grupo de enfermeiras auditoras, que os processos de socialização foram, especialmente, importantes para a carreira de uma das profissionais, e por isso, tornou-se objeto desse estudo: conhecer as influências dos processos de socialização, primária e secundária na trajetória profissional de uma enfermeira auditora (EA).

\section{ABORDAGEM METODOLÓGICA}

Personagens marcantes foram biografadas inúmeras vezes ao longo da história da Enfermagem, por terem contribuído para o reconhecimento e desenvolvimento da própria profissão. Florence Nigthingale, por exemplo, representa um desses grandes nomes, e por isso, é intitulada patrona da Enfermagem. Do mesmo modo, Ana Neri, considerada a primeira enfermeira brasileira, e tantas outras personagens importantes foram retratadas por terem sido pioneiras em determinadas ações e experiências, que impactaram significativas mudanças para a sociedade.

No entanto, biografar a vida de um indivíduo é mais que narrar uma história. Cabe ao pesquisador descortinar as nuances da história biografada e colocar em palavras suas influências, sucessos, insucessos, desafios e superações ao longo do caminho (PEREIRA; NÓBREGA-THERRIEN; SILVA, 2020). Para isso, recorrer às lembranças do sujeito é uma importante estratégia, pois "[...] a 
memória é a chave que permite ao pesquisador apropriar-se do acontecimento pela via interpretativa de quem o viveu e que, ao narrar, reconstrói o vivido à sua maneira e torna o fato imortal." (ESQUINSANI, 2012, p. 221).

Neste sentido, optou-se pela abordagem metodológica na linha das pesquisas autobiográficas, na qual a biográfico-narrativa pautou a construção desse estudo, vez que "[...] no momento em que houver uma narrativa, "existe relato de vida", e é suficiente." (BERTAUX, 2018, p. 338).

O método biográfico é recente na área das ciências da educação, mas foi uma perspectiva metodológica largamente utilizada pelos sociólogos da Escola de Chicago nos anos 1920 e 1930, que caiu em desuso nas décadas posteriores. Seu uso foi retomado por volta da década de 80 e 90, momento que os autores buscaram compreender o processo de formação docente, tanto no aspecto social quanto individual, considerando não só a subjetividade da vida cotidiana, como a sua carreira e o seu percurso profissional (BOLÍVAR, 2002; BUENO, 2002).

A pesquisa biográfica e narrativa em educação surge então em movimento contrário ao modo científico dominante, vez que buscou compreender e capturar os detalhes dos significados da vida, que contemplam os sentimentos, os desejos e as motivações que constituem as vicissitudes humana (BOLÍVAR, 2002). Neste sentido, as biografias de professores assumiram ponto central na construção do conhecimento na pesquisa em educação, e permitiram um processo de formação mais eficaz, já que possibilitaram refletir e recuperar no tempo-espaço das narrativas, aspectos importantes à investigação do desenvolvimento profissional, que também é pessoal.

A pesquisa biográfica-narrativa, em razão disso, consiste em uma abordagem ou perspectiva específica, um método científico (BOLÍVAR, SEGOVIA e CRUZ, 2016). Isso porque se trata de uma metodologia que propõe a construção do saber científico a partir da investigação realizada epistemologicamente em conjunto ao pesquisador e pesquisado. Dentro dessa dinâmica, o papel do pesquisador é interpretar os significados atribuídos aos acontecimentos e experiências vividas pelos pesquisados. Estes, por sua vez, são responsáveis por narrar suas experiências, (re)construídas e (re)significadas ao longo da vida. Assim, ambos, pesquisador e pesquisado, assumem posição central no desenvolvimento de um novo conhecimento (BOLÍVAR, 2007).

O método biográfico-narrativo é, portanto, o resultado de um processo dialógico e interativo, a partir de uma história de vida que ao ser compartilhada e narrada, permite o registro das vicissitudes de uma identidade narrativa, construída e ressignificada individual e socialmente ao longo da trajetória (BOLÍVAR, (2002); BRAGANÇA, (2009)). Processo que faz dos indivíduos seres únicos e singulares (PASSEGI, (2011); DELORY-MOMBERGER, (2012)).

Para a construção (auto)biográfica, utilizou-se um formulário sociodemográfico e de formação da participante, e a entrevista biográfica, realizada em três momentos. O primeiro constitui-se da livre narrativa da participante idealizada por meio da seguinte questão desencadeadora: "Considerando que o processo de formação do enfermeiro constitui-se essencialmente para a prática assistencialista, conte-me como aconteceu sua trajetória profissional na Auditoria de Enfermagem (AE)?".

A partir da análise das narrativas, os dados (auto)biográficos foram organizados em sínteses esquemáticas - Biogramas (BOLÍVAR, (2002); SÁ; ALMEIDA, (2004)), nos quais os incidentes críticos, na percepção da pesquisadora, foram apresentados as participantes no segundo momento da entrevista, denominado entrevista devolutiva. 
A luz de Franco (2013, p. 314), incidentes críticos são "[...] rupturas proporcionadas por crises ou eventos críticos que afetam as pessoas e provocam alterações no curso de sua vida".

O Biograma é um recurso utilizado para organização e exposição dos dados narrativos, em ordem cronológica, possibilitando maior compreensão dos participantes no momento da apresentação dos relatos, para validação dos mesmos (BOLÍVAR; SEGOVIA; CRUZ, 2016; BOLÍVAR, 2002).

Outros autores utilizaram esse instrumento e apresentaram os dados ordenados sequencialmente em sete colunas lineares, categorizadas em fases da trajetória profissional, cronologia em anos, idade vital, idade profissional, acontecimentos/incidentes críticos, valoração dada aos acontecimentos e trechos que expressam os sentidos atribuídos a esses relatos, como pode ser observado na figura 1 (GUIA, 2019; NAVARENHO, 2019; GRILO, 2017; SOUZA, 2016; ALVES, 2015; SÁ e ALMEIDA, 2004).

Tabela 1 - Biograma

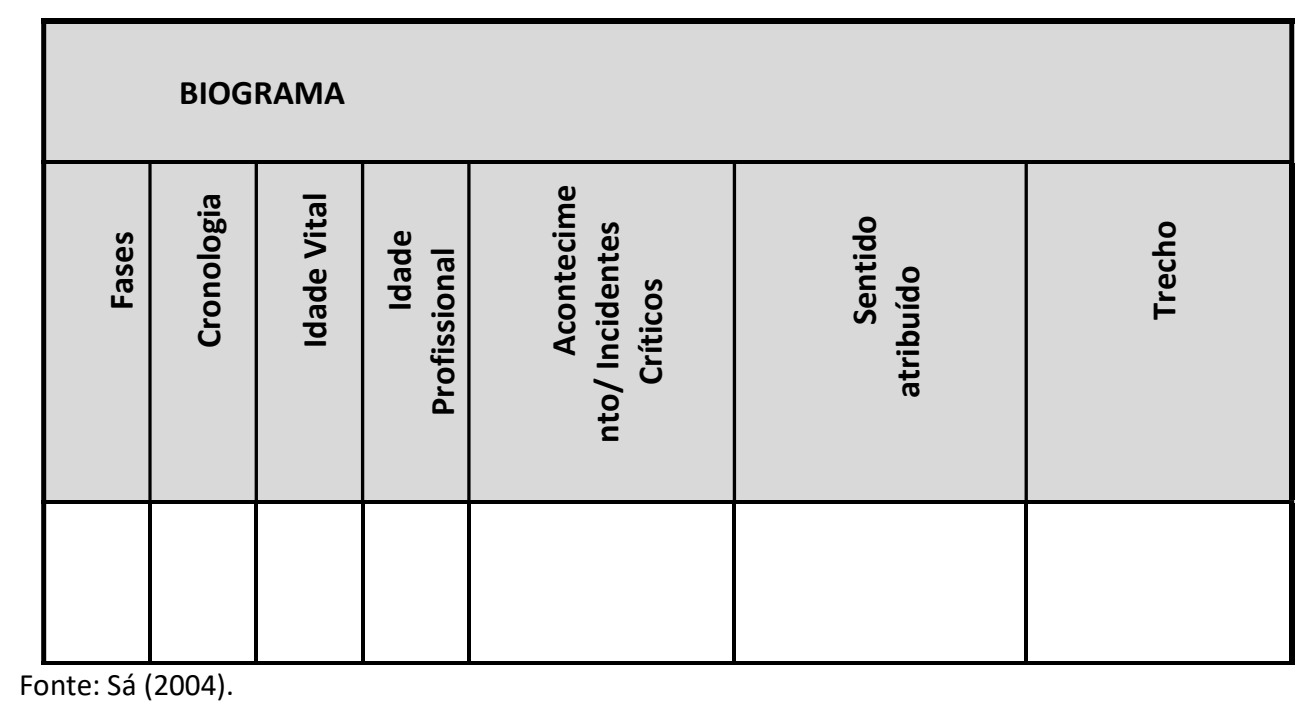

A partir da confecção desse Biograma, denominado como versão inicial, procedeu-se para o segundo momento da entrevista, chamada de entrevista devolutiva, dedicado à apresentação dos dados biográficos aos participantes, que na percepção do pesquisador destacaram-se como eventos críticos em sua trajetória de vida pessoal e profissional, para confirmarem, refutarem e / ou acrescentarem novas informações, permitindo o detalhamento de fatos que se fizer necessário maior aprofundamento. [...] O fato de um acontecimento, pessoa ou fase adquirir um caráter "crítico" não depende do pesquisador, mas de que o próprio sujeito lhe dê esse caráter - direta ou contextualmente - no seu relato (por exemplo, "foi uma coisa muito importante na minha vida") (BOLÍVAR, 2002, p.191).

Para Szymanski (2000) a entrevista devolutiva tem como objetivo submeter à apreciação do participante a transcrição da entrevista, como uma pré-análise do material coletado por parte do pesquisador. Esse procedimento confere autenticidade e fidedignidade à produção, e permite a partir de uma condição de reflexividade, maior aproximação entre pesquisador e pesquisado.

Para Delory-Momberger (2016) este é o sentido da construção do saber biográfico, realizado de modo conjunto e colaborativo, pesquisador-pesquisado (DELORY-MOMBERGER, 2016). 
Por fim, para a confecção do Biograma final foi necessária uma terceira entrevista. Assim, apresenta-se os resultados desse estudo na seção em sequência.

\section{RESULTADOS E DISCUSSÃO}

Ao concluir a análise dos resultados da pesquisa de mestrado, a história de uma das participantes se destacou. Isso porque a escolha da profissão foi especialmente importante para sua trajetória profissional, pois marcou sua história de vida pessoal e profissionalmente.

Marie ingressou no curso técnico de enfermagem aos 20 anos de idade e, posteriormente, confirmou sua escolha profissional no momento em que ingressou na graduação em Enfermagem. Seu percurso foi marcado pela importante influência familiar e escolar, que por meio de lembranças e memórias compartilhadas do passado a auxiliaram no momento da escolha da profissão. Esse fato a direcionou para qual caminho seguir, tal como pontuam Berger e Luckmann (2004) e Setton (2005).

Para Marie, recordar momentos vividos na infância e, principalmente, pessoas que marcaram sua vida, como sua mãe, possibilitou compreender que poderia transformar as experiências vividas no núcleo familiar em oportunidades de trabalho, como pode-se observar:

[...] fiz magistério, acabei de me formar fui lá na Secretaria de Educação, quando eu cheguei lá vi uns 200 professores, um avançando no outro por causa de aula. Eu falei: Meu Deus o que isso, né? E aí voltei aqui em Cunha não tinha um curso, não tinha nada, comecei a trabalhar no Tudo da Roça e aí minha mãe que falou pra mim, minha mãe falou pra mim: por que você não faz um curso de enfermagem? Não faltar emprego [...] isso porque quando eu tinha 9 anos, minha avó sofreu um acidente, minha avó e meu avô, meu tio e minha tia, então faleceu os 3 e ficou só a minha avó. Então eu tinha 9 anos e fui pra cuidar dela. Ela ficou muito tempo na UTI, ficou cheia de curativo, tipo assim, eu não tinha nojo [...] fazia curativo na minha avó, dormia com a minha avó, nunca tive essas coisas de ah, tenho nojo, nunca tive! [...] Aí eu entrei pra fazer o curso técnico de enfermagem no Senac, trabalhava no comércio e viajava pra fazer o curso (Marie).

Ao compartilhar sua história, lembrou-se que o magistério não era a melhor escolha profissional naquele momento. Sentiu-se insegura diante do desafio que enfrentaria para pleitear uma vaga com mais de cem profissionais para uma única entrevista de emprego, e retornou para casa decepcionada e sem perspectivas. Já em casa, sua mãe a lembrou da assistência que havia prestado a avó e que fora fundamental para a sua recuperação e reabilitação, dando a ela a esperança de uma nova oportunidade de trabalho.

O grupo primário de socialização destacou-se para Marie como importante grupo de apoio em seu processo de escolha, assim como para 16 ex-participantes de um programa de orientação profissional (SANTOS, 2005). A família não só foi considerada como determinante na realização desse projeto, como propiciou suporte emocional para o enfrentamento dos conflitos, incertezas e adaptações comuns a essa fase que retrata um período de significativa transformação pessoal (GONDIM, 2002; HUTZ; BARDAGIR, 2006; BOHOSLAVSKY, 2015).

O acontecimento inoportuno que afetou sua família influenciou a participante a atuar na área da saúde e ingressar no curso técnico de enfermagem, que pagou com o emprego no comércio. Ambas as experiências vividas, de cuidar da avó doente e trabalhar no comércio para pagar os estudos e, com isso, mudar de área profissional, fortaleceram quanto ao caminho que iria trilhar. 
Antes de ingressar em uma faculdade ou curso técnico o indivíduo pode-se direcionar para atividades na área do comércio, a fim de contribuir para o sustento da família e/ou subsidiar seus estudos (BERNARDIM, 2014; RODRIGUES, 2018). Essa realidade foi experimentada por Marie, que teve que redimensionar sua escolha e seus planos de vida em virtude de ocorrências não planejadas, como ao identificar que a profissão que havia escolhido não era o melhor caminho para iniciar a vida profissional. Isso porque o mercado de trabalho para o magistério na época estava sobrecarregado de profissionais e, com isso, não seria fácil conseguir um lugar entre tantos que também sonhavam se estabelecer nessa área.

A mudança de planos vivida por Marie exemplifica como eventos críticos e inusitados surgem ao longo da vida, sendo necessário adaptações e redimensionamento, pessoal e profissional, para superar as situações não planejadas, que influenciam e alteram o curso de vida, afirma Woods (1993) apud Almeida (2009). Esses acontecimentos podem estar associados, por exemplo, a perda de emprego, mudança de área de atuação ou escolha profissional, e afetam o desenvolvimento e implicam em reorganizações pessoais, como as vividas por Marie:

[...] acabei de terminar o curso, vim aqui na Santa Casa, conheci a irmã Lourdes, fiz 15 dias de estágio e ela me chamou que gostou muito do meu estágio, queria que eu trabalhasse aqui [...] Marie.

A escolha pelo curso técnico é opção para muitos jovens, principalmente quando há apoio dos pais, comum nos casos em que ainda existem dúvidas sobre qual profissão seguir e também quando não há condições financeiras para subsidiar um curso de nível superior. Isso faz com que o curso técnico profissionalizante se torne um projeto que possibilite a realização de seus sonhos, como o ingresso no universo acadêmico (BURNIER et al., 2007; BERNARDIM, 2014).

Alguns jovens ingressam na vida acadêmica antes de iniciar a vida profissional, outros buscam entrar no mercado de trabalho tão logo se profissionalizam em escolas técnicas, pois acreditam ser o modo mais rápido e que oferece melhor oportunidade (LUCHIARI, 1996; BERNARDIM, 2014; BOHOSLAVSKY, 2015). Isso se confirmou na trajetória da entrevistada, que decidiu fazer o curso técnico devido à facilidade de acesso ao mercado de trabalho, já que na época havia a necessidade de mais profissionais para atuarem na área da Enfermagem.

Conhecer a área escolhida por meio de um curso intermediário permite familiarização com a área e incentiva a busca por profissionalização. Assim, o jovem reafirma suas escolhas e a carreira que deseja seguir. Pode ocorrer, também, que venha a ter desinteresse pela área ou pelo curso, partindo para novas possibilidades, até que se identifique com alguma atividade específica (LUCHIARI, 1996; SOARES; AGUIAR; GUIMARÃES, 2010; RODRIGUES et al., 2014).

Esse fato se confirmou na trajetória da EA, que iniciou sua vida profissional na área do magistério, migrou para o curso técnico de enfermagem e desenvolveu sua carreira ao ingressar na graduação de Enfermagem. Marie se identificou de fato com a profissão e sentiu o desejo de crescer pessoal e profissionalmente, a partir da importante influência profissional que teve no ambiente de trabalho, como segue nos discursos:

[...] a irmã Lourdes, enfermeira do hospital, pegou e falou pra mim quando eu era técnica de enfermagem: Faz curso superior, entra na faculdade, você leva jeito, é boa. E isso foi uma coisa que marcou muito a minha vida, ela me ensinou tudo (Marie).

Ao recordar o início da carreira percebeu que essa fase da vida profissional ficou marcada pelas dificuldades técnicas enfrentadas. Porém, a orientação profissional que teve de sua chefia 
imediata não só representou importante ponto de apoio como constituiu referência para suas práticas assistenciais, vez que lhe proporcionou segurança para ingressar no curso superior. Ao aprofundar os estudos, Marie conheceu gradativamente as futuras atividades, o campo de trabalho, as perspectivas de remuneração financeira e de ascensão social que poderia ter, confirmando assim suas escolhas profissionais.

Esse processo de transformação do indivíduo ocorre a partir das constantes mudanças e redimensionamentos, parte do construto dinâmico que é viver, promovendo desenvolvimento e imprimindo personalidade e identidade, à medida que se identifica com seu fazer profissional. Nota-se a influência da socialização do grupo secundário, e de pessoas marcantes na trajetória profissional da EA, confirmando suas escolhas à medida que se identificava com a profissão. Contudo, apesar das influências do processo de socialização primária, a identificação com a área profissional também influencia a escolha do curso e é considerada no momento da argumentação e decisão pelo caminho que deseja seguir, para realização de projetos ao longo da vida (VOLPATO et al., 2011).

Desse modo, pode-se inferir que não só o grupo primário de socialização foi importante na escolha da carreira da participante, mas também, ou principalmente, as influências do grupo secundário. Isso porque o indivíduo já amadurecido consegue visualizar com mais clareza as oportunidades que lhe surgem, por isso é considerado como fator influenciador de destaque, pois define, altera e confirma as trajetórias ou carreiras profissionais (OJEDA et al., 2009; NEPOMUCENO; WINTER, 2010).

Para Marie a escolha pela profissão se deu por intermédio de pessoas que significaram os momentos vividos de modo particular, em diferentes temporalidades e que contribuíram para o seu desenvolvimento, tanto no campo pessoal como no profissional. Assim, modificou suas decisões até se sentir segura quanto a carreira que gostaria de seguir, por isso cabe destacar a importância da mudança de categoria na área da Enfermagem nesse processo. Isso porque conferiu-lhe particular integração do conhecimento adquirido no início da carreira (como técnica de enfermagem) à nova concepção profissional (como enfermeira), como relatado por Souza (2015).

Nota-se que são distintos os processos de formação de cada categoria de enfermagem (auxiliar de enfermagem, técnico de enfermagem e enfermeiro), com abordagens teóricasmetodológicas específicas para cada atribuição profissional (SOUZA; PAULA, 2016). Por sua vez, esses processos de formação reverberam importantes influências na identidade profissional de cada indivíduo, na imagem que deseja repercutir na sociedade e no desejo por reconhecimento e valorização da profissão (Fernandes e Souza, 2017).

Para Marie todas essas etapas foram fundamentais na concepção de sua identidade pessoal e profissional. Considerou cada experiência como um degrau na construção de sua carreira e agregou valor emocional em cada fase de sua formação, compreendendo o significado do vivido em cada temporalidade e da sua importância na construção de sua imagem, seus valores, sua crença, seu caráter e postura profissional. Características que a motivaram cada vez mais a fazer Enfermagem para além de suas expectativas locais, incentivando-a a transformar e (re)construir seu caminho a todo instante.

Ao buscar mudança de categoria, enfermeiras e enfermeiros objetivam ascensão, reconhecimento social e profissional, pois trata-se de uma conquista que é almejada, em virtude de sua própria história, pela profissão Enfermagem (ORTIZ; PLATIÑO, 1991; BELLAGUARDA et al., 2016; MACHADO et al., 2019). Compreendem a importância do trabalho realizado anteriormente 
no processo de desenvolvimento de competências necessárias ao ofício da profissão. Essa experiência confere familiaridade às novas práticas de enfermagem e marca o momento de progressão na carreira, ao proporcionar satisfação pessoal por essa conquista (MEDINA; TAKAHASHI, 2003; DUBAR, 2012; COLENCl; BERT, 2012).

As instituições de ensino superior constituem peças chaves nesse contexto e acrescentam, por meio de abordagens de conteúdos metodológicos com aplicações teórico-prática-científica e normativas curriculares legais, particular desfecho na proposição de conhecimento e competências, no sentido de preparar o enfermeiro para ser um profissional ativo e com formação de qualidade, que possam atender as suas próprias expectativas e aquelas inerentes ao sistema de saúde brasileiro (CARDILLI; SANNA, 2015). Entretanto, é fato que preparar um profissional com tais qualificações é um grande, senão o principal desafio a ser superado por essas instituições de ensino (BELLAGUARDA et al., 2013).

Outra questão que se destacou foi que ao se formar, Marie rememorou o compromisso assumido com sua primeira chefe, que the pediu para permanecer em sua cidade e assistir a população tão logo se graduasse como enfermeira, como segue no relato a seguir:

[...] a irmã Lourdes disse: mas quando você se formar não é pra você fazer isso que a maioria faz, ir embora pra cidade maior! Você tem de trabalhar pro seu povo. Falou desse jeito pra mim, ela foi embora e falava assim pra mim [...] basicamente eu fiz faculdade, primeiro porque eu vi que eu tinha jeito pra Enfermagem mesmo e eu queria crescer dentro na área. Eu sempre quis crescer, eu nunca quis ficar estagnada. Aí eu fiz Enfermagem, depois quis fazer especialização porque nunca gostei de ficar sem estudar (Marie).

À medida que compartilhava sua história foi possível perceber o impacto desse compromisso em sua vida, haja vista que jamais se ausentou do município, onde nasceu e cresceu, para tentar se estabelecer em outros lugares, seja para buscar melhores condições de trabalho ou melhores condições salariais. Não que não tenha havido o desejo, mas sentiu-se particularmente comprometida com aquela mulher que contribuiu para o seu processo de formação, assim como para a profissional que se tornou.

A partir disso, construiu laços afetivos em suas experiências e relembrou, com sentimento de profunda gratidão, os conselhos que direcionaram sua trajetória profissional, confirmando a influência e interferência do grupo profissional de socialização em sua vida (DUBAR, 2005). Laços que manteve até os dias de hoje.

Já como enfermeira, também vivenciou dificuldades técnicas. Ao se formar, a parte gerencial foi seu maior desafio, embora, mais uma vez, essa situação foi amenizada pela orientação profissional recebida por outra pessoa importante em sua vida. $\mathrm{O}$ aconselhamento a direcionou no caminho a seguir no contexto em que atuava, no sentido de desenvolver competências e habilidades gerenciais necessárias à prática administrativa da profissão:

[...] a gente da enfermagem, desde a época da faculdade o que se visa muito, é o cuidado, é o assistencialismo. A gente sai da faculdade muito despreparada, praticamente a aula que a gente tem de administração quase que é nada, então você sai sem nenhuma visão administrativa. Então foi esse o sentimento que eu tinha logo que eu me formei, por exemplo, eu cai no hospital assim, eu me senti como se eu fosse um técnico de enfermagem melhorado [...] essa parte administrativa fica muito aquém [...] a gente sai da faculdade muito imaturo, além de imaturo, pouco preparado, a gente é como se fosse um enfermeiro generalista, é pra cuidar com aquela visão holística da área assistencial, já a parte gerencial que a gente deve ter como enfermeiro eu não tinha, e como eu tive uma 
professora enfermeira que foi como uma mestra pra mim, ela que foi me direcionando e eu fui vendo também quais eram as carências no hospital que eu trabalhava (Marie).

Poucos profissionais conseguem ter o apoio e a orientação que Marie teve. Mais uma vez sentiu-se muito grata por isso, já que sua professora mestra a preparou para a profissional que precisava ser. Sentiu-se amparada nos momentos em que mais precisou para colocar em prática todo seu conhecimento e aprender aqueles que ainda não tinha. Período que precisou ser paciente e dedicada para dar continuidade a permanente qualificação profissional, comum à profissão.

Pessoas marcantes, como colegas de profissão e professores, podem ser referências profissionais que se almejam ser consideradas importantes no processo de constituição de competências e da identidade profissional de enfermeiras e enfermeiros, que está em contínua construção. A influência de pessoas significativas nas trajetórias das participantes contribuiu para o seu desenvolvimento, ao incentivá-las a crescer tanto no aspecto pessoal como no profissional, pois "[...] não há como separar o eu pessoal do eu profissional, eles se entrecruzam e se interrelacionam mutuamente" comenta Nóvoa (1995, p. 17).

Neste sentido, a entrevista de pesquisa biográfica permite a compreensão da singularidade dos fatos, situações, relacionamentos e significações, tanto quanto as interpretações das vicissitudes dadas por cada indivíduo à sua história, e que o transforma em um ser único e singular (DELORY-MOMBERGER, 2012). Corroborando para isso, a socialização profissional contribui para o processo de transformação do sujeito, já que potencializa suas motivações e desejos de ascensão na profissão, inflamados pelo anseio de melhor remuneração e posição social (FERREIRA JÚNIOR et al., 2018).

$O$ ingresso na $A E$ foi um momento pontual na trajetória profissional de Marie, influenciado pela socialização profissional. Esse acontecimento proporcionou ascensão profissional na carreira e permitiu a participante (re)pensar suas escolhas e (re)significar o saber fazer e o saber ser na Enfermagem. Isso porque a expertise adquirida ao longo dos anos de atuação na área assistencial trouxe-Ihe motivações, oportunidades e desafios, que a direcionaram para um novo caminho.

A AE é uma especialidade que se tornou essencial nas instituições de saúde, vez que visa qualificar a assistência de enfermagem e controlar custos operacionais direcionados a esses serviços. Desse modo, sendo a Enfermagem em maior número de profissionais na área de saúde, promover o aperfeiçoamento profissional e controlar os gastos hospitalares constitui importante recurso de gestão (CLAUDINO et al., 2013 e COSTA; FOSSATI, 2015).

Por outro lado, a prática da AE pode proporcionar ao enfermeiro reconhecimento social e valorização profissional, possibilitar melhor remuneração, status social e qualidade de vida, ao contrário do que ocorre na prática assistencial, em que há condições salariais precárias, exaustiva carga horária de trabalho, com equipes compostas por reduzido número de profissionais e/ou profissionais ainda inexperientes, além da subvalorização ou nenhum reconhecimento profissional (GENTIL, 2009).

Na pesquisa de mestrado que originou esse estudo, intitulada Trajetórias Profissionais de Enfermeiras Auditoras: incidentes críticos e motivações na escolha profissional, observou-se que ingresso na $A E$ se mostrou para as participantes como um evento motivado pela busca por melhores condições de trabalho, remuneração e status profissional. Para Marie, foi marcada pelas dificuldades vividas no cotidiano na prática assistencial, diante das precárias condições orçamentárias para a prestação dos serviços, quanto aos suprimentos de insumos necessários à 
assistência hospitalar que a motivaram a buscar conhecimento, a fim de propor melhorias para a instituição na qual se dedicava há anos.

A falta de profissionais para auditar prontuários fez com que Marie se visse diante do dilema: ter que tomar a iniciativa de executar tal atividade, em razão das frequentes glosas nas contas hospitalares da instituição em que trabalhava e comprometiam o retorno financeiro do serviço prestado, e acumular mais uma função no trabalho.

[...] Antigamente era o Estado que auditava nossas contas, de repente começa a Secretaria de Saúde auditar, eles não estavam preparados pra auditar essas contas, e aí vinha às glosas pra gente, ninguém sabia dizer pra nós porque estava glosado, era meio que, tinha que descer a seco na nossa garganta a justificativa deles, e eu disse: eu não posso aceitar isso, eu preciso fazer um curso para entender isso, entender pra poder discutir isso, onde está o erro, eu não posso simplesmente acatar o estão falando, porque a gente já vive com orçamento escasso, com repasse do SUS deficitário e ainda vem as glosas? [...] realizo a auditoria de todos os prontuários sozinha, $100 \%$ deles passam na minha mão, hoje praticamente as minhas glosas são zero, mas tenho que conciliar com as atividades da administração (Marie).

Ter que atuar com número reduzido de EA ou não poder contar com o suporte desses profissionais para realizar auditoria de prontuário é uma realidade em inúmeras instituições brasileiras, já que é uma área ainda em expansão no campo da saúde. Por isso, quase sempre exige dos enfermeiros mais qualificados, capacitação profissional para realizar esse serviço, visto ser uma atividade em destaque em virtude dos benefícios para o desenvolvimento e crescimento das instituições de saúde.

Essa realidade também foi experimentada pela participante e acarretou demasiada sobrecarga de trabalho, exigindo inteligência emocional para resolver os problemas relacionados ao gerenciamento de enfermagem e subsistência da instituição, e para atender à nova demanda de trabalho referente às atividades de $A E$. Isso a fez se sentir sobrecarregada diante de tanto trabalho, contudo, a relação de afeto e satisfação no fazer profissional na instituição a levou a acumular mais uma função.

A AE para Marie significou ampliação de seus conhecimentos profissionais e conferiu-lhe status profissional no trabalho. Porém, não obteve maior remuneração salarial ou melhores condições de trabalho em virtude disso, pelo contrário, o compromisso de implementar ações educativas junto à equipe, no sentido de contribuir para o desenvolvimento de melhorias no trabalho dos profissionais de enfermagem, acarretou-lhe considerável comprometimento, pessoal e profissional.

Nota-se que as experiências memorizadas não só constituíram importante motivação para o ingresso na Enfermagem, em nível técnico e superior, como possibilitou à EA, durante o processo de formação, identificar-se com o fazer profissional na área da saúde e o desejo pela prática profissional diferenciada.

Cabe considerar ainda, que sua trajetória foi construída em meio a continuidades e descontinuidades próprias do percurso de vida, marcada por acontecimentos significativos, caracterizados por rupturas que ocasionaram crises e alterações em seu caminho, representadas pelos sucessos, insucessos e / ou recuos ao longo de sua história. 


\section{CONCLUSÃO}

Considerando a profundidade da narrativa generosamente compartilhada por Marie, constatou-se que a escolha da profissão foi um acontecimento memorável em sua vida e o início da construção de sua identidade, que é pessoal e profissional. Assim, por intermédio de pessoas que marcaram momentos vividos, e que de modo particular em diferentes temporalidades estimulou seu crescimento e desenvolvimento quanto indivíduo.

As experiências memorizadas não só constituíram importantes motivações para seu ingresso na Enfermagem, em nível técnico e superior, como possibilitaram identificar-se com o fazer profissional na área da saúde, ao longo de seu processo de formação.

Os resultados mostraram que o desejo de conquistar melhores condições no trabalho direcionou a $E A$ para área da $A E$, o que trouxe o sentimento de ascensão social e valorização profissional na carreira, mesmo sem melhores remunerações. Para Tenani et al. (2014), isso se explica em virtude de a satisfação profissional estar mais associada ao reconhecimento do trabalho que se realiza e à promoção do desenvolvimento dos profissionais, que a melhores remunerações.

Para Marie, executar a AE transformou seu saber-fazer, no saber-ser e saber-pensar Enfermagem. Ela se desafiou a conquistar uma nova prática profissional e ingressar na $A E$ a fez sair de sua zona de conforto, que estava pautada nas atividades tradicionais da Enfermagem, enraizadas na prática assistencial e gerenciamento do serviço de enfermagem. Foi preciso repensar suas ações e se integrar em um novo contexto socialmente instituído na área da saúde, na qual a $A E$ permitiu compreender que não existe cuidado sem gerenciamento de recursos financeiros e logísticos, qualidade dos serviços prestados, comprometimento e qualificação profissional.

Desse modo, conclui-se que a EA, a luz de Shinyashiki et al. (2006), construiu uma nova trajetória profissional, a partir da criticidade e reflexividade vivida em cada experiência ao longo de sua carreira.

No entanto, cabe pontuar a importante responsabilidade que instituições de ensino superior têm no processo de formação e preparação dos profissionais para atuarem no sistema de saúde brasileiro. É essencial e necessário cada vez mais implementar abordagens metodológicas que ampliem discussões relacionadas a $A E$, para o direcionamento à novos horizontes e perspectivas para além do sucesso e lucratividade dos serviços de saúde. É preciso promover o reconhecimento do EA pelo seu conhecimento, pela importância do trabalho que realiza, e não só pelos resultados financeiros que proporciona para as instituições de saúde (NUNES et al., 2010). Certamente, isso não só promoverá o desenvolvimento da Enfermagem, como contribuirá para a posição de destaque que merece, assim como, para o conhecimento, crescimento e evolução profissional da especialidade da AE.

\section{REFERÊNCIAS}

ALVES, Jurema Silvia de Souza. Gestores escolares: incidentes críticos nas trajetórias profissionais. 2015. 231 p. Dissertação (Mestrado em Desenvolvimento Humano: Formação, Políticas e Práticas Sociais) - Universidade de Taubaté, Taubaté-SP, 2015. 
ALMEIDA, Laurinda Ramalho de. O incidente crítico na formação e pesquisa em educação. Educação e Linguagem, v. 12, n. 19, p. 181- 200, 2009.

ALMEIDA, Maria Elizabeth B. de; SILVA, Maria da Graça Moreira da. Currículo, tecnologia e cultura digital: espaços e tempos de web currículo. Revista e-curriculum, São Paulo, v.7, n.1, abr., 2011.

BELLAGUARDA, Maria Lígia dos Reis; PADILHA, Maria Itayra; PERES, Maria Angélica de Almeida; PAIM, Lygia. Enfermagem profissão: seu status, eis a questão. Revista Enfermagem UERJ, Rio de Janeiro, 2016; v. 24, n. 2, p. e8591, 2016. Disponível em: <

http://dx.doi.org/10.12957/reuerj.2016.8591>. Acesso em: 20 mai. 2020.

BELLAGUARDA, Maria Lígia dos Reis; PADILHA, Maria Itayra; NETO, André de Faria Pereira; PIRES, Denise; PERES, Maria Angélica de Almeida. Reflexão sobre a legitimidade da autonomia da enfermagem no campo das profissões de saúde à luz das ideias de Eliot Freidson. Escola Anna Nery Revista de Enfermagem, Rio de Janeiro, v. 17, n. 2, p. 369-374, 2013.

BERGER, Peter L.; LUCKMANN, Thomas. A construção social da realidade: tratado de Sociologia do conhecimento. Tradução de Floriano de Souza Fernandes. 24 ed. Petrópolis, Editora Vozes, 2004.

BERNARDIM, Márcio Luiz. Quem são e o que buscam na escola os estudantes da educação profissional e do ensino médio noturno? XANPED Sul, Florianópolis, p. 1-22, 2014.

BERTAUX, Daniel. O "relato de vida" como método das ciências sociais. [Entrevista concedida a] Luciano Rodrigues Costa e Yumi Garcia dos Santos no ano de 2018. Tempo Social, Revista de Sociologida da USP, v. 32, n. 1, Jan. - Abr., p. 319 - 346, 2020.

BOLÍVAR, Antonio. Profissão Professor: o itinerário profissional e a construção da escola. Bauru São Paulo: Edusc, 2002.

BOLÍVAR, Antonio. 0 esforço reflexivo de fazer da vida uma história. Revista Pedagógica, v. 11, n. 43, p. 12-15, 2007. Disponível em: <http://loja.frupoa.com.br/revistapatio/artigo/6678/o-esforcoreflexibo-de-fazer-da-vida-uma-historia.aspx>. Acesso em: 14 abr. 2018.

BOLÍVAR, Antonio Botía; SEGOVIA, Jesús Domingo; CRUZ, Manuel Fernández. Pesquisa biográficanarrativa em educação. Guia para investigar o campo. Materiais auxiliares Classe Série/Research, v. 2. 2016.

BOHOSLAVSKY, Rodolfo. Orientação Vocacional: a estratégia clínica. 12. ed.. Trad. José Maria Valeije Bojart. São Paulo: Martins Fontes, 2015.

BRAGANÇA, Inês Ferreira de Souza. Histórias de vida e formação de professores/as: Diálogos entre Brasil e Portugal. p. 1-595. Tese [Doutorado] - Universidade de Évora, Portugal, 2009.

BURNIER, Suzana; CRUZ, Regina Mara Ribeiro; DURÃES, Marina Nunes; PAZ, Mônica Lana; SILVA, Adriana Netto; SILVA, Ivone Maria Mendes. História de vida de professores: o caso da educação profissional. Revista Brasileira Educação, v. 12, n. 35, mai. - ago., 2007. 
CARDILLI, Carolina V. C.; SANNA, Maria C. Acontecimentos que antecederam a federalização da Escola Paulista de Enfermagem. Escola Anna Nery Revista de Enfermagem, Rio de Janeiro, v. 19, n. 1, p. 24-32, 2015.

COLENCI, Raquel; BERT, Heloísa Wey. Formação profissional e inserção no mercado de trabalho: percepções de egressos de graduação em enfermagem. Revista Escola Enfermagem USP, São Paulo (SP), v. 46, n. 1, p. 158-66, 2012.

DELORY-MOMBERGER, Cristine. Abordagens metodológicas na pesquisa biográfica. Tradução de Anne-Marie Milon Oliveira. Revista Brasileira de Educação, V. 17, n. 51, set. - dez., 2012.

DELORY-MOMBERGER, Cristine. Pesquisa biográfica ou a construção compartilhada de um saber do singular. Revista Brasileira de Pesquisa (Auto) Biográfica, Salvador, v. 01, n. 01, p. 133-147, jan.-abr. 2016. Disponível em:

<http://www.revistas.uneb.br/index.php/rbpab/article/view/2526/1711>. Acesso em: 29 jun. 2018.

DUBAR, Claudine. A socialização: construção das identidades sociais e profissionais. São Paulo: Martins Fontes, 2005.

DUBAR, Claudine. A construção de si pela atividade de trabalho: a socialização profissional. Caderno de Pesquisa, São Paulo, v. 42, n. 146, p. 351-367, ago. 2012. Disponível em: <http://www.scielo.br/pdf/cp/v42n146/03.pdf>. Acesso em: 15 out. 2018.

DURAN, Marília Claret Geraes. Profissão docente: desafios de uma identidade em crise. Revista Brasileira Pesquisa Formação Docente, v. 2, n. 2, jan./jul. 2010. Disponível em: <http://formacaodocente.autenticaeditora.com.br>. Acesso em: 10 jun. 2019.

ESQUINSANI, Rosimar Serena Siqueira. Entre percursos, fontes e sujeitos: pesquisa em educação e uso da história oral. Educação e pesquisa, São Paulo, Universidade de São Paulo, v. 38, n. 1, p. 217 -228, 2012. Disponível em: <https://doi.org/10.1590/S1517-97022012005000001>. Acesso em: 20 mai. 2020.

FERNANDES, Carla Natalina da Silva; SOUZA, Maria Conceição Bernardo de Mello e. Docência no ensino superior em enfermagem e constituição identitária: ingresso, trajetória e permanência. Revista Gaúcha de Enfermagem, Porto Alegre, v. 38, n. 1, p. e64495, 2017.

FERREIRA JÚNIOR, Antonio Rodrigues; FONTENELE, Matheus Eduardo Passos; ALBUQUERQUE, Rosalice Araújo de Sousa; GOMES, Francisco Meykel Amâncio; RODRIGUES, Maria Eunice Nogueira Galeno. A socialização profissional no percurso de técnico a enfermeiro. Trabalho, Educação e Saúde, Rio de Janeiro, v. 16, n. 3, p. 1.321 - 1.335, set. - dez., 2018.

GRILO, Alessandra de Cássia. A trajetória docente na Engenharia Biomédica, incidentes críticos e motivações na escolha profissional. 2017. 127 f. Dissertação (Mestrado em Educação e Desenvolvimento Humano: Formação, Políticas e Práticas Sociais), Universidade de Taubaté, Taubaté-SP, 2017. 
GUIA, Paula Ferreira do Amaral. Pequenas empresas e grandes mulheres: trajetórias profissionais de empreendedoras. 2019. 209f. Dissertação (Mestrado em Educação e Desenvolvimento Humano: Formação, Políticas e Práticas Sociais) - Universidade de Taubaté, Taubaté-SP, 2019.

GONDIM, Sônia Maria Guedes. Perfil profissional e mercado de trabalho: relação com a formação acadêmica pela perspectiva de estudantes universitários. Rio de Janeiro: Nova Fronteira, 2002.

HUBERMAN, M. O ciclo de vida profissional dos professores. In: NÓVOA, A. (Org.). Vidas de professores. 2. ed, p. 31-61. Porto: Porto Editora, 1995.

HUTZ, C. S., BARDAGIR, M. P. Indecisão profissional, ansiedade e depressão na adolescência: a influência dos estilos parentais. Psico-USF (Impresso), Campinas, v. 11, n. 1, p. 65 - 73, 2006.

LUCHIARI, Dulce Helena Soares. Os desejos familiares e a escolha profissional dos filhos. Revista Ciência Humana, Florianópolis (SC), v. 14, n. 20, p. 81-92, set. 1996.

MACHADO, M. H. Maria Helena et al. Mercado de trabalho e processos regulatórios - a Enfermagem no Brasil. Ciência \& Saúde Coletiva [online], v. 25, n. 1, p. 101-112, 2019. Disponível em: <https://doi.org/10.1590/1413-81232020251.27552019>. Acesso em: 13 jan. 2020.

MEDINA, Neuma Vital Julca; TAKAHASHI, Regina Toshie. A busca da graduação em enfermagem como opção dos técnicos e auxiliares de enfermagem. Revista da Escola de Enfermagem USP, São Paulo, v. 37, n.4, p. 101-8, 2003.

MIRANDA, Adílio Renê Almeida et al. Trabalho, socialização e identidade: um estudo com professoras gerentes de uma universidade pública. Avaliação (Campinas), v. 20, n. 2, p. 353-375, jul., 2015.

NAVARENHO, Priscila Santos da Silva. Trajetória docente na Fisioterapia: viver, narrar e formar. 2019. 168f. Dissertação (Mestrado em Educação e Desenvolvimento Humano: Formação, Políticas e Práticas Sociais) - Universidade de Taubaté, Taubaté, 2019.

NEPOMUCENO, Ricardo Ferreira; WITTER, Geraldina Porto. Influência da família na decisão profissional: opinião de adolescentes. Psicologia Escolar Educacional, São Paulo (SP), v. 14, n. 1, p. 15 - 22, set., 2010.

NÓVOA, Antonio. Os professores e a histórias da sua vida. In: NÓVOA, A. Vidas de Professores. 2 ed., Porto, Portugal: Porto Editora, p. 11 - 30, 1995.

NUNES, Carina Maria et al. Satisfação e insatisfação no trabalho na percepção de enfermeiros de um hospital universitário. Revista Eletrônica de Enfermagem [Internet], v. 12, n. 2, p. 252 - 257 , 2010. Disponível em: <https://www.revistas.ufg.br/fen/article/view/7006/6902>. Acesso em: 05 jan. 2020.

OJEDA, Beatriz Sebben et al. Acadêmicos de enfermagem, nutrição e fisioterapia: a escolha profissional. Revista Latino-Americana de Enfermagem, Ribeirão Preto (SP), v. 17, n. 3, mai.-jun., 2009. 
ORTIZ, Gloria Cecilia Mejía; PLATIÑO, Néstor Albereto Manrique. El stress y su relacion com las condiciones de trabajo del personal de enfermaria. Investigación y educación en enfermería, Medellin, v. 9, n. 2, p. $83-99$, set., 1991.

PADILHA, Maria Itayra; NELSON, Sioban; BORENSTEIN, Miriam Sussekind. As biografias como um dos caminhos na construção da identidade do profissional da enfermagem. História, Ciencias, Saúde - Manguinhos, Rio de Janeiro, v. 18, supl. 1, p. 241 - 252, dez., 2011. Disponível em: $<$ http://www.scielo.br/scielo.php?script=sci arttext\&pid=S0104-597020110005000013 >. Acesso em: 20 mai. 2020.

PASSEGI, M. C. A experiência em formação. Educação, Porto Alegre, v. 34, n. 2, p. 147-156, mai.ago., 2011. Disponível em:

<http://revistaseletronicas.pucrs.br/ojs/index.php/faced/article/view/8697/6351>. Acesso em: 15 abr. 2018.

PEREIRA, Mariza da Costa; NÓBREGA-THERRIEN, Silvia Maria; SILVA, Andréa da Costa. Maria Grasiela Teixeira Barroso: Desenvolvimento Profissional na Enfermagem Cearense. Revista Brasileira de Pesquisa (Auto)Biográfica, Salvador, v. 5, n. 13, p. 229 - 242, jan. - abr., 2020.

RODRIGUES, Sônia Sousa Almeida. Democratização ou Elitização? Um estudo sobre o perfil dos estudantes ingressantes do Ensino Médio Integrado ao Técnico do Instituto Federal do Norte de Minas Gerais (IFNMG) Campus Januária. Dissertação (Mestrado) - Área de concentração em Sociedade, Ambiente e Território, Universidade Federal de Minas Gerais / Instituto de Ciências Agrárias. Montes Claros, 2018. $126 \mathrm{f}$.

RODRIGUES, A. C. et al. A terapia cognitiva comportamental com adolescentes em busca da construção do projeto de vida, através da escolha profissional. 2014. Disponível em: <http://www.professorthometavares.com.br/download.pdf $>$. Acesso em: 05 de dez. de 2019.

SÁ, Maria Auxiliadora Ávila dos Santos; ALMEIDA, Laurinda Ramalho de. Devolutiva de entrevistas: o biograma na pesquisa em educação. Psicologia da Educação, São Paulo, v. 19, $2{ }^{\circ}$ sem., p. 185 192, 2004. Disponível em: <http://pepsic.bvsalud.org/pdf/psie/n19/n19a10.pdf>. Acesso em: 31 mai. 2018.

SANNA, Maria Cristina. Biografia. In: OGUISSO, Taka; CAMPOS, Paulo Fernando de Souza; FREITAS, Genival Fernandes de. Pesquisa em História da Enfermagem. Barueri: Manole, 2011. p. 301 - 338.

SANTOS, Larissa Medeiros Marinho dos. O papel da família e dos pares na escolha profissional. Psicologia em Estudo [online], v. 10, n. 1, p. 57 - 66, 2005. Disponível em: <http:// www.scielo.br/scielo.php?script=sci arttext\&pid=S1413-73722005000100008\&lng= pt\&nrm=isso>. Acesso em: 15 dez. 2019.

SETTON, Maria da Graça Jacintho. A particularidade do processo de socialização contemporâneo. Tempo social, São Paulo, v. 17, n. 2, p. 335-350, nov. 2005. Disponível em: <http://www.scielo.br/pdf/ts/v17n2/a15v17n2.pdf $>$. Acesso em: 20 out. 2018. 
SOARES, Dulce Helena Penna; AGUIAR, Fernando; GUIMARÃES, Beatriz da Fontoura. O conceito de identificação no processo de escolha profissional. Aletheia, v. 32, n. 7, p. 134 - 146, 2010.

SOUZA, Dalva Maria Ribeiro. Envelhecimento nas trajetórias dos professores da educação profissional: incidentes críticos, expectativas e projetos no período pré-aposentadoria. 2016. $128 f$. Dissertação (Mestrado em Desenvolvimento Humano: Formação, Políticas e Práticas Sociais) Universidade de Taubaté, Taubaté-SP, 2016.

SOUZA, Gláucio José. Construção da identidade do enfermeiro: a experiência da profissionalização. 2015. 244 f. Dissertação (Mestrado em Educação e Desenvolvimento Humano: Formação, Políticas e Práticas Sociais) - Universidade de Taubaté, Taubaté, 2015.

SOUZA, Gláucio José; PAULA, Maria Angela Bocara de. Construção da identidade do enfermeiro: revisão integrativa da literatura. Revista Rede de Cuidados em Saúde, Rio de Janeiro, v. 10, n. 1, p. 1-17, 2016.

SHINYASHIKI, Gilberto Tadeu et al. A Socialização profissional: estudantes tornando-se enfermeiros. Revista Latino-Americana de Enfermagem, v. 14, n. 4, jul. - ago., 2006. Disponível em: <Disponível em: http://www.redalyc.org/articulo.oa?id=281421863019>. Acesso em: 05 dez. 2019.

SZYMANSKI, Heloisa. Entrevista reflexiva: um olhar psicológico para a entrevista em pesquisa. Psicologia da Educação. São Paulo, v. 11 / 12, p. 193 - 215, 2000.

TENANI, Mariana Neves Faria et al. Satisfação profissional dos trabalhadores de enfermagem recém-admitidos em hospital público. Revista Mineira Enfermagem, v. 18, n. 3, p. 585 - 591, jul. set., 2014.

VELOSO, Elza Fátima Rosa; DUTRA, Joel Souza; NAKATA, Lina Eiko. Percepções sobre carreira inteligentes: diferenças entre gerações $y, x$ e baby boomers. Revista de Gestão, São Paulo, n. 23, p. 88-98. 2016.

VOLPATO, Gildo et al. Desafios da profissão e problemas na formação de professor na percepção de acadêmicos de Artes Visuais e Matemática. Educação em Perspectiva, Viçosa (MG), v. 2, n. 2, p. 223-45, jul./dez. 2011.

${ }^{1}$ Uma versão reduzida deste artigo foi publicado no VI Congresso Internacional da Rede ACINNET 2020.

${ }^{1}$ A shortened version of this paper was published at the VI ACINNET Network Conference 2020. 